\title{
Research on Process Management of Cabin Service in Chinese Civil
}

\section{Aviation Enterprises}

\author{
Qixing Li and Yuan Li \\ College of Music ,Jiangxi University of Technology
}

Keywords: Cabin service; Business; Process management

\begin{abstract}
The service quality is very important for Chinese civil enterprises. How to improve the service quality in civil enterprises depends on the organizational features, actual situation of enterprise as well as objective internal and external environment. Process management is one of hottest domestic administrative disciplines in our country, so how to put process management theories into administrative practice in service enterprises effectively has become an important part of their competitiveness. Civil enterprises in our country belong to industry with intensive service. Over the years, comprehensive quality management has been implemented, which can't satisfy Chinese civil aviation enterprises' competitive advantage among international civil aviation field. With value creation as the core, we can learn from current advanced process management so as to meet Chinese civil aviation enterprises' pursuit for specific customers and special service, which can help to establish a framework of cabin service process for Chinese civil aviation enterprises.
\end{abstract}

\section{Introduction}

Under the economic globalization, civil aviation enterprises in various countries have accelerated their expansion in international market. Cabin service management has received attention from various civil aviation enterprises with the constantly deepening of reform and revolution since China joined the WTO. However, there are still many problems existing in domestic civil aviation enterprises.

Research on quality management and process management in civil aviation enterprises home and abroad has achieved some results; but however, it is a relatively new subject to integrate service quality management with process management regarding cabin service management and to establish a system cabin service process management with less guiding theories. In the paper, process management of cabin service in civil aviation enterprises will be deeply studied by taking cabin service process management in our country as an example combined with the development situation of current civil aviation service. In this way, a series of systematic theories can be refined and concluded, which has realistic significance for the long-term development of civil aviation enterprises; and meanwhile it is a beneficial complement theoretically so as to promote a better and faster development of civil aviation enterprises.

Since the 1960s, service management has become a new important research field for management home and abroad, which has achieved rich results. Marketing researchers in North Europe have conducted massive effective studies and proposed lots of new models, concepts and tools according to characteristics of marketing service, service output and service transmission. Besides, they have concluded these research results as "service marketing". Service marketing, as a research field of 
service management, has provided advantageous condition for the formation of service management theoretical system.

The core of service management is service quality. First scholars from North Europe have carried out pioneering study on the connotation and property of service quality. In addition, American marketing college has also carried out a specific ten-year research on service quality. Some remarkable and influential research results have come out consecutively, which has pushed the perfection and development of service management system.

Since the 1980s, Heskett, scholar and expert from service research center of Harvard University Commercial College as well as Vanderbilt University explored in related studies in 1994 the variables affecting profits as well as their mutual relations, which has indicated the relations among variables specifically and obviously with the establishment of a "service profit chain" structure. This structure is especially important for studying service problems and discovering reasons affecting service quality.

Rust explained benefits as well as means to improve service quality, argued the relationship between service quality and enterprise benefits. From the perspective of service quality, high quality can result in high customer satisfaction, which can achieve high efficiency but low cost. High quality can reduce the cost with higher profits; besides, high quality can attract competitive customers, producing market shares and benefits.

The Balanced Score Card system proposed by Kaplan and Norton, American Management scientists has explained how strategic execution connects financial targets, customer value proposition, business process and enterprise intangible assets together.

IDS Scheer company proposed the ARIS housing structural mode for business process, which forms a multiple view concept for process modeling through constructing business process view, including organizational structure, data information, function and product service.

Anders Gustavsson proposed that competitive advantages of customer service should be established based on process collaboration and resource integration, forming an enterprise activity combination that is difficult to be copied and imitated by rivals.

\section{Cabin service process management}

Service management studies how to conduct management and achieve success for enterprises in competitive environment. There are also many scholars and experts home have conducted theoretical study on service management, including analysis on information technology, service interaction as well as mutual quality, service profit chain during service quality management; meanwhile, they also conduct comparison between service product marketing and manufacturing product marketing, which has achieved certain theoretical results.

Service management comes from many disciplines, which is an administrative activity related to many disciplines and fields including business management, production operation, organizational theory, human resources management and quality management science. It is a necessary trend from scientific management to service management. Although it has not been an independent theoretical system, it has provided guiding principles for enterprises' sustainable competitive advantages.

The features of cabin service can be concluded as the following five aspects. First, it has heavy sense of responsibility for safety; second, it has special service environment; third, it has strong technology and complicated service contents; fourth, it has distinctive individualized service; fifth, it has high demand for service staff's comprehensive quality. Through related theories of quality 
management, process management and service management, combined with the definition and features of cabin service, definition of cabin service process management can be concluded as follows. According to service standards of civil enterprises, from the perspective of company strategies, customer demand and business by taking cabin as service place, it can conduct process planning and construction, establish process organizational institute, clarify the responsibility of process management, monitor and review process operation performance with appropriate process reform, which can achieve a constant dynamic and systematic method for organizational business performance.

Process management is a systematic method with the center of standardized and end-to-end brilliant business process, and with the aim of promoting business performance constantly. It is an operative positioning description, which refers to process analysis, process definition and redefinition, resource allocation, time arrangement, process quality and efficiency assessment and process optimization and so on. Since process management is designed for customer's need, so this process can be optimized with the change of internal and external environment.

The core of process management is process, which is the operation basis of any enterprise. All business in an enterprise should be driven by process just like human's blood process, which can transmit information data from one person or department to other staff or departments according to certain condition. When corresponding result is achieved, it will return to related person or department again. In an enterprise, different departments, different customers, different staff and different suppliers are collaboratively cooperated with process. Corresponding data may be brought with during the operation of process, including information transferring of document, product, financial data, projects, tasks, personnel and customers. If the process is operated smoothly, then this enterprise can't be operated successfully too.

Process management is the negation and revolution of traditional professional management. Compared to functional management, process management has five advantages. First, it is superior to administrative orientation. The organizational structure of process management is centralized by process. The goal of enterprise is oriented by customer and service. Second, it has more efficient management. The input and output of product as well as information have a short time and low efficiency. Third, the management has superior adaptation with fast reaction to administrative task and structural change. Fourth, it is superior on the whole. Process management is all-way management with network internal management. Internal network has been unified with external network with more attention to the neglected external network. Fifth, it has superior collaboration. The collaboration, which is centralized by process, gives equal emphasis on internal process collaboration and external collaboration, especially for the overlooked external process collaboration. The five advantages are central performances of the connotation of process management. The goal of process management is to promote control degree by specific management. Work efficiency can be optimized and improved through process. Invisible knowledge can become obvious through system or standards. The resources can be allocated rationally through process management so as to achieve a management copy.

Under the principles of process management, from the perspective of customer service, concepts with customer as center should be established. That is, customers and goals of the process should be defined; besides, under emergent and special situation, principles to judge right and wrong should be clarified; in addition, result should be concerned with the formulation of performance indicators 
based on process output so that everyone during the process can possess common goal with agreement on customers and results.

The levels of process management can be divided into process standard, process optimization and process reformation. The process standard sorts out enterprise process with definition of contents during each section as well as connection relationship among various sections so as to form close business connection, which is suitable for normal operation of all enterprises. Process optimization fits for all periods of an enterprise, which is a continuous optimization of process as well as continuous review on enterprise process and optimization process, and thus process system in an enterprise can be perfected independently. Process reformation is review and redesign of enterprise process, which is suitable for revolution and reformation stages of enterprises, during which there is change, merger \& acquisition of treatment structure, change of commercial mode as well as emergence of new technology, new craftsmanship, new products and new markets and so on. The goal of process management is to improve customers' satisfaction and company's market competitive capability finally so as to increase enterprises' performance. The overall goal of process improvement can be decided according to enterprises' development stages. Under the guidance of general goal, improvement goal for each business as well as unit process can be reformed again.

The purpose of process management is to make process adapt to industrial business environment and embody advanced and practical management ideas. By learning from excellent enterprises, company's strategies can be integrated effectively. Besides, with the introduction of cross-department coordination mechanism, the cost, time, quality and service for customers can be optimized on the whole with a better comprehensive competitiveness.

In China, in the middle and late 1980s and the beginning of 1990s, civil aviation enterprises began to establish consecutively with a short development stage. In the long term, as the administrator of civil aviation industry, Civil Aviation Administration of China has always possessed strict standards for both cabin service and ground service, and even detailed to varieties and quantities of drinks they provide. Objectively, such strict management has resulted in a "qualified management" mode, according to which civil aviation enterprises should guarantee their cabin service quality ideologically, which has greatly restricted the promotion of service standards with less attention to customers' demand. Thus, there is a very serious homogenization phenomenon for cabin service in Chinese civil aviation enterprises. Their service procedure and contents are almost the same.

After years of marketization operation, Chinese civil aviation industry has formed its own unique administration system. The airport is responsible for guaranteeing the flight missions of airlines and waiting service of ground customers; while civil enterprises are responsible for transportation of customers and goods. Such kind of coordinated and independent work has monopolized ground service business, which makes civil aviation enterprises incapable of providing corresponding ground service. In reality, airport has long been a monopoly position of ground service, but it has weak consciousness of service; while civil aviation enterprises have obvious better marketization consciousness than airport as supplier of aviation and transportation. Although civil enterprises have vigorously studied market state with the development of corresponding service products, whether their results can be pushed forward is determined by current guarantee capability and subjective will of airport.

According to survey, complaints from most customers come from abnormal flight. Due to the particular characteristic of aviation transportation, flight can be easily affected by artificial factors. Therefore, it is difficult to fly normally by plan. By data statistics, abnormal flights of civil aviation 
enterprises account for nearly $20 \%$, withing which $90 \%$ delay time is spent in cabins, which leads to direct conflict between cabin staff and customers. Thus, cabin service is more difficult to satisfy customers.

Among administrative theories, human resource is prior resource for quality management system. Quality and attitude of cabin service staff can decide the service quality of civil aviation enterprises. Due to historical reasons, cabin service personnel have always possessed a kind of advantageous psychology, lacking a sense of service. They do not realize their responsibility is to offer service without subjective service spirit. Besides, many staff in civil aviation enterprises get in through special relations, so they are lack of ability of offering qualified service and service awareness relying on their background.

At present, overall consumption environment and consumers in civil aviation industry in our country have not been mature. There is not enough trust between cabin service staff and customers, which makes it inconvenient for communication. On the contrary, customers may be compromised under the exorbitant demand and violent behaviors by civil aviation enterprises, and they may undertake some unnecessary responsibilities finally. Some customers have no idea of safeguarding legal rights, so they often go against laws during legal right protection. These cases may be reported and commented by media unilaterally, which may affect common cabin service order and strengthen the difficulty of problems solving for cabin service.

To sum up, the reasons for current imperfect cabin service in civil aviation enterprises are due to purely departmentalized management of cabin service without combining service process with management as well as the implementation of service process management regardless of management system, industrial division of labors or abnormal aviation flights; at the same time, staff quality and service consciousness as well as consumption environment and consumers themselves are immature. In addition, the incomplete and imperfect service process has also brought certain difficulty for service process management.

A smooth implementation and enforcement of cabin service process management should be guaranteed from the following aspects.

The concept of service process management can be changed by permeating service process management concept centralized on value creation in civil aviation enterprises for cabin service. Administrative departments for cabin service, administrative departments for establishing and implementing service process management system, research and development departments for service process management standards and certification and some other supporting departments should permeate administrative concept step by step so that related departments, civil aviation enterprises and personnel can have a good knowledge about this framework, and thus establishment and implementation of service process management system can reach an agreement consciously.

Theoretical knowledge on service process management system with value creation as the center should be expanded as possible as we can so that service process management system can be operated based on certain theoretical knowledge. Cabin service process management system should be established and implemented with value creation as the center with a comprehensive theoretical understanding of framework for process management system from the whole to structure. It should be comprehensively connected to service management, process management, management process and functions which are related to process management system as theoretical basis, so establishment and implementation of cabin service process management system can be fully prepared so as to construct framework specifically. 
The current administrative system should be improved first so that cabin service process management system in civil aviation enterprises can enter into a virtuous cycle. Organizational flattening can be highlighted by turning process management into department management with the establishment of organization for cabin service process management. The current decision layer, management layer and operation layer can be turned into decision layer and management organization so as to shorten the hime by shrinking report and approval procedure. Thus, civil aviation enterprises can create maximum benefits in a short time.

By adopting various measures, cabin service in civil aviation enterprises can be promoted to an international level with constant exchanges home and abroad. Meanwhile various standards of national standard system can be further updated and corrected for cabin service management in civil aviation enterprises. By this way, their research and development for standards as well as operative capability can be tested by markets home and abroad.

An integrated research and development mechanism can be established for service management development and cabin service process management. Research and development is relatively an important activity for cabin service process management system during operation. Besides, an interactive mechanism should be established for service management research and development as well as cabin service process management system so that service process management system can embody the demands for these activities constantly.

Preparation for the establishment and implementation plan of cabin service process management system in civil enterprises should be made. Besides, establishment and implementation plan for cabin service process management system in civil aviation enterprises should be prepared; and meanwhile the overall time table should be determined. From the perspectives of external influences, construction of cabin service process management itself as well as supports of establishment and implementation for various parts of operational mode, construction and training of cabin service process management can be enhanced. Thus, cabin service process management system in civil aviation enterprises can be perfected with certain basis for construction and implementation.

The unified and coordinated work in cabin service management institute of civil enterprises should be brought into play, and meanwhile large airlines in our country should be coordinated to result in an integrated service process. That is, they should possess a unified big process but different small processes. Meanwhile, establishment and implementation of operation mode for cabin service process management system can be promoted by strengthening certification as well as research and development activities. Coordinated cooperative mechanism can be established between standard research and development and certification to form information sharing and technology consultancy mechanism of standard and certification, which can contribute to a closer combination of standard and certification.

Research results of cabin service process management system in civil aviation enterprises should be vigorously promoted so as to own a reputation home and abroad. Besides, the research on cabin service process management should be enlarged by determining the position of research, improving the reputation and constantly increasing its influence.

Civil aviation enterprises in our country belong to typical service-intensive industry, in which cabin service is qualified service offered to customers as well as demand for acquiring business interest and social reputation. During providing service, different contact points can be produced. With comprehensive analysis on different contacting points, improvement and controlling strength can be enlarged. 
With the constant increase of customers as well as great improvement of living standard, market has been further divided with different demands for value-added services. Customers from each level should be analyzed by civil aviation enterprises so as to adopt corresponding measures to meet customers' need. While improving service standard of different levels, less burden should be put on enterprises. As for high-end customers and businessmen, individualized service shall be provided for them. As for customers who seldom take a plane, common sense of flight should be advocated, guided and assisted so as to meet their basic need for trip. During the exploration of individualized and common service rules, conclusion and analysis should be made constantly so as to master and form service laws for customers of different levels specifically, during which these customers can be turned into loyal customers gradually. In addition, with constant improvement of living standard, more and more people choose to go out by plane, and thus individualized service should be offered to high-level customers accordingly so that most customers can enjoy service of high quality, which can greatly increase customers' satisfaction and loyalty degree.

Innovation and management committee should be established by civil aviation enterprises so as to lead and coordinate the innovation. First, during the stage of production innovation, cabin service innovation and management committee should establish a special institute used to track competitive rivals and internal service. Through this tracking, customers' demand can be explored in advanced service to see whether they are satisfied or not. As long as a new service measure is launched, some experts will be sent to try and estimate the measure to see if it is necessary to introduce it or not. Besides improving innovation from opponents, service innovation and management committee should also encourage all staff to participate in innovation actively. Staff should be gathered to discuss freely without any restriction so that they can have full imagination. The accepted creation can receive development funds and rewards. In addition, service innovation development group should be established to research, design and try out service innovation. The development team shall be coordinated by service innovation management committee, ensuring a rational personnel allocation. As for the investment of innovation result, service innovation and management committee should track timely and know about customers' satisfaction degree on new service as well as opinions to improvement with constant improvement.

\section{Conclusions}

As for the essence of service process management, it has embodied the systematic and integrated innovation and application of scientific management methods in enterprises. The reasons why service process management can achieve significant effect lie in the following aspects. First, service process management can achieve outstanding improvement since enterprises have chosen improvement chances and determined improvement goals from the perspective of strategies, which can guarantee a breakthrough improvement on service process management. In addition, the effect of implementation has been guaranteed with the formation of scientific plans as well as strict estimation in improvement. At last, the implementation of service process management needs to be supported by high leading levels with participation, so the establishment of basic organizational structure for service process management is an necessity for a long-term success, and it is also a necessity for creating an environment and culture for management innovation. 


\section{References}

[1] BRITISHAIR, ysFACTB00K.2001.London,2002

[2] Meng Zhao rong et al. Operational Mode of World Well-Known Airlines. Beijing, China Press of Civil Aviation. 2001

[3] Ye Wanchun et al. Marketing Management of Service. Beijing, China Renmin University Press. 2003

[4] Zhou Yongliang. Strategies for Well-Known Brands' Competition. Beijing, Press of Economic Management, 2002

[5] Gong Zhen et al. Studies of Consumer Behaviors. Dalian, Press of Northeast University of Finance, 2002

[6] He Xiaoqun, Six Sigma As Well As Guidelines for Its Leading-In. Beijing, China Renmin University Press, 2003

[7] He Xiaoqun, Controlling Technology of Six Sigma. Beijing, China Renmin University Press, 2003

[8] Niu Hongwei, Zhao Liming. Research on Service Recovery Management in Service Enterprises. Journal of Liaoning College of Technology, 2005, 72、:62-65

[9] Chen Lihua, Kang Hongen. Study on Service Recovery Management in Airlines, 2002,3:44一 45

[10]Ping Xianbing. Discussion on Development Trend of Service Industry in China. Journal of Inner Mongolia Agricultural University. 2005,4:430一 433 